\title{
Dialogue is the alpha and the omega: the Asia-Europe Foundation (ASEF)
}

\author{
Dominique Girard
}

Published online: 14 September 2010

(C) Springer-Verlag 2010

When the Asia-Europe Meeting (ASEM) was created in 1996, a full vision of time was involved:

The past, because if Europe and Asia shared the privilege of having given birth to most of the civilisations, the religions, philosophies and concepts which have survived until the twentieth century, they had also been tragically opposed by a long period of confrontation: colonial exploitation and imperialist aggression had divided the huge Eurasian continent where, since time immemorial, contacts had been an exceptional source of mutual enrichment and fascination.

The present, because globalisation does not allow any region or country to live in isolation even from its most distant real or potential partners. Europe needed to organise its relations with Asia beyond the bilateral ties it entertained with Asian nations and even beyond the links it has started establishing as an entity with economic partners whose growth was becoming more and more impressive.

The future, because although nobody could then predict what the notion of "emerging powers" would encompass a dozen years later, it was already understood that after the demise of the Soviet Union, Asia's renaissance would be the next determining event in the world's history.

This probably explains why, despite many difficult tests, from the 1997 economic crisis in Asia to the question of its enlargement and to the sometimes apparent lack of productivity of its official functioning, ASEM has lasted until now, and does not stop attracting new candidates: its eighth Summit is welcoming Australia, New Zealand and Russia this October 2010, and that suffices to show the enduring validity and relevance of this unique informal dialogue structure. Let us be clear: the world also needs more directly efficient bodies to tackle new issues and to integrate a quickly evolving balance of power. G7, G8, G20, the transition is now an

Ambassador Dominique Girard

Executive Director

D. Girard $(\bowtie)$

Asia-Europe Foundation (ASEF), 31 Heng Mui Keng Terrace, 119595 Singapore, Singapore

e-mail: executiveoffice@asef.org

URL: www.asef.org 
acquis, and so is the feeling that the evolution is on track for a long time. But what has also emerged as evident is the absolute necessity for world leaders to know and understand one another's outstanding problems to be able to find solutions to global issues. In this respect, interregional dialogue is an indispensable facility, and ASEM's sustainability directly derives from that fact. In spite of - or thanks to Asia's diversity, it constitutes an amazing forum for leaders to exchange, test, develop as well as improve ideas and proposals that could not germinate in a formal setting. It facilitates personal contacts across the variety of partners, including inside the two groups of countries, and clarifies problematics. It also gives birth to actual projects which, in many fields, from education to inter-civilisation dialogue, human rights or culture, help governments to work together across regional divides.

ASEM's founding fathers, however, thought that providing a better structure to facilitate relations between leaders should be supplemented by encouraging an effective dialogue among the people from Asia and Europe. That was the origin of the Asia-Europe Foundation (ASEF), an even more innovative concept and a realisation that to date remains unique worldwide. There were some interesting precedents to this decision, like the huge effort launched by the French and the German governments in the 1960s to develop civil society links between the two former enemies to get rid, at least in the new generations, of the old antagonisms and prejudices. The European integration would never have succeeded without the "real" people from the two biggest countries of the continent accepting each other with their differences and even their past hostility. Many more attempts at getting rid of "traditional" oppositions between individual countries had since been conducted, with more or less success. However the lack of such efforts has always resulted in enduring difficulties between governments as popular feelings are often impossible to ignore by political leaders when the latter, in the worst scenarios, do not systematically exploit the former for their own interests. On the contrary, a strong organised civil society support to the improvement of bilateral relationships has often proven extremely useful to resolving past differences.

In the mid-1990s, the problem between Asia and Europe was not direct hostility and antagonism. It was rather indifference, ignorance and, particularly on the European side, a growing anxiety in front of a globalisation process in which Asia was increasingly playing a more important role. The three phenomena were equally disturbing if a true development was to intervene in the relations between the two regions. Indifference was common among societies that had encountered deep transformations and were discovering a much more complex world than what it had been in the previous 50 years. Ignorance was not new, but had morphed into a real handicap when everybody's life could be affected by changes happening in countries or regions on the other side of the planet. Keeping the old vision of China, India, or practically all other Asian nations at the turn of the millennium, or looking at Europe as a mere trading block when both continents were undergoing huge changes resulting in new forms of involvement in world affairs, was equally counterproductive. It risked pitting populations against each other by a crude reflex of selfprotection. The redistribution of economic and technological cards entailed by globalisation could also be interpreted as defeat or victory depending on who benefitted from it and how the impact on the peoples' lives was managed. Compounded with the bitter memories of the past, those "psychological" obstacles 
could be detrimental to the development of a more consistent, sustainable and mutually profitable overall relationship.

ASEF was thus created as an instrument of dialogue to improve mutual understanding and cooperation between civil societies of Asia and Europe and to channel their preoccupations to the ASEM leaders. It was an extremely ambitious target, if only because the very concept of civil society could contain a host of different meanings, or little meaning at all. How would it be possible to reconcile so different historical traditions, cultural practices, political systems, economic situations into an effective or even a reasonable cooperation? The answer came with experience and time, to a large extent thanks to the dedication and subtlety of Ambassador Tommy Koh, ASEF's first Executive Director, and also to the intelligence and good faith of the ASEM/ASEF partners themselves. ASEF had to be a platform for real dialogue where nobody would lose its soul or forget its values, but where all would come armed with respect and tolerance. All would have a real desire to debate, to work together to register concrete results, to discover the others and/or to improve sometimes slowly and painfully, their ability to understand each other and to reinforce a sincere communication. Governed by consensus among the representatives of the ASEM partners (the participating countries - they are now 46 - plus the ASEAN Secretariat and the European Commission), ASEF is managed by a team totally imbued with the principle that dialogue is the alpha and the omega of the Foundation's mission and that it must be promoted and facilitated as its utmost priority and responsibility.

To approach its target, ASEF therefore needs to abide by specific rules which contribute to making it, as was said before, a unique organisation. Its projects are always bi-regional. They always involve external partners whose expertise guarantee the quality of the projects, contribute to supplement ASEF's limited resources and ensure that most of ASEF's actions are followed up by further developments and by active inclusions of its alumni. ASEF respects broad thematic priorities defined by ASEM's summits or ministerial meetings which provide political consistency to its actions. It sometimes brings into its projects officials from partner countries or regional organisations, but always in association with representatives from civil society: academia, NGOs, the media, youth organisations, foundations, local authorities, artists, scientists, etc. ASEF projects follow a variety of formats, in view of the specificity of the topics or the framework of the events: from the "Talks on the Hill" involving at most 20 participants to debate a sensitive topic to a large conference comprising a number of workshops often organised by invited partners, from a very focused seminar gathering specialists of urban development to a major web portal on cultural activities and policies in both regions, etc. ASEF's strategy aims at tackling sensitive and important issues, sometimes at the explicit request of the ASEM leaders. However, ASEF tries to never duplicate projects which are already implemented by other bodies or are not relevant to its "Asia-Europe" mission. Similarly, ASEF's publications are geared to support its mandate and follow its guidelines, particularly regarding sustainability, neutrality and dialogue.

ASEF is not a think tank, an academic institution, an NGO, a financing agency or the promoter of anybody's vested interests. It is a political tool designed to help two regions to develop, beyond their immediate interests, their ability to communicate and cooperate with the support and the involvement of their people: a huge and modest task, exhilarating and arduous, generating a remarkable enthusiasm among 
participants to its projects and alumni, as well as among ASEF's own small team of seconded diplomats and young experts. Whatever their nationality, ASEF's staff members are proud of their contribution to the spirit of dialogue, respect and exchange which permeates all programmes.

Cynics can of course argue that ASEF's role is marginal, superficial and irrelevant to the hard core issues that political leaders and economic actors have to handle in an uncertain world of brutal competition and global challenges. With a small budget fed by the voluntary contributions of ASEM partners, it can be described as weak, fragile, unknown to most members of the "civil society" that it is supposed to address and which makes up more than $70 \%$ of the world population. Some can contend that its dual nature - Asian and European, official and non-governmental makes it timid or powerless regarding the big ideological or cultural divides between its stakeholders. Maybe. But self-appointed realists ultimately have to recognise that particularly in this "post-modern" era, nothing can be achieved against - or in the ignorance of-populations' sensitivities and feelings. Without a measure of the idealism that feeds and justifies ASEF's mission, the intellectual equation of international debates will always remain unsolved. The ongoing global negotiation on climate change shows how much, whatever their ideological inclinations, governments' policies are based on their ability, or lack thereof, to accommodate their peoples' yearning for growth, security and faith in their future. Anything done to reduce misunderstandings, prejudice, and anxieties as well as to promote educated dialogue, contacts, mutual trust and knowledge will facilitate the necessary bargaining between national or regional authorities. That is exactly what ASEF is supposed to do: As a facilitator and a "multiplier", it targets institutions and/or individuals whose exchanges will help clarify issues, establish connections, instill confidence or just knowledge to further improve the conditions for higher level interaction. It can do so thanks to its ability, after 13 years of building reliable networks of participants, advisers, experts and "believers", to propose its hundreds of partners well-focussed and relevant actions with the approval and the support of ASEM's authorities. Its programmes and projects may not be known by the general public, but in most cases, they have a long-lasting impact on the different circles they concern and are followed by even more ambitious or extended activities. Complacency has no room in such a system, be it at the initial stage of designing projects or selecting partners, in the implementation or during evaluation and followup. ASEF has on itself a critical look, which is duly supplemented by the many processes whereby its stakeholders and contributors verify the wisdom of its choices and the efficiency of its projects.

The inclusion of Australia, New Zealand and Russia in ASEM and ASEF is a new and exciting challenge for the Foundation. It will increase its workload and broaden its perspectives. More than ever, it will test ASEF's capacity to deliver on its mandate by identifying and mobilising new partners to strengthen dialogue among the vastly diverse civil society realm of the new ASEM. ASEF will have to reinforce its ability to propose common reflections on issues as well as to organise more and bigger meetings among people, particularly young ones. Given the strategic potential of the Asia-Europe relationship, it looks forward to the impulse that the Brussels Summit will provide to the global interactions that are to follow, at the regional level in Asia and Europe, and worldwide, starting with the Seoul G20 meeting. 